\title{
Review of Performance Improvement of VSS FLC and NN MPPT Photo Voltaic Power System
}

\author{
Chandramouli $\mathrm{A}^{\mathrm{a}, 1}$, Arulmurugan $\mathrm{R}^{\mathrm{b}}$ and Sivachidambaranathan ${ }^{\mathrm{c}}$ \\ ${ }^{a}$ Dept of Electrical, Sathyabama Institute of Science Technology, Chennai \\ ${ }^{b}$ Professor, Dept of Electrical, Sanjivani College of Engineering, Kopargaon \\ ${ }^{c}$ Professor, Dept. of Electrical, Sathyabama Institute of Science Technology, Chennai \\ Tamilnadu, India
}

\begin{abstract}
In this paper guides in the fuzzy logic and Neural network variable step size Incremental conductance maximum power point tracking controller were analyzed as well suggested on further work. Firstly, the Fuzzy Logic Control (FLC) controller based hardware system derived paper were discussed followed by Neural Network (NN) based VSS Inc-Cond were discussed in the second half. In the first paper derived simple FLC I.e short, medium and long distance were considered to derive the 25 rules. The input of FLC are current and voltage, the output of FLC is duty cycle or D. The duty cycle apply into variable step Inc-conductance method to find the optimal point of the PV system. Further discussed experimental block diagram of FLC- Inc-Cond system. At the end of the paper authors compared various hardware to show tabulations. In the second half, initially discussed conventional Inc-Cond, followed by general Fuzzy logic controller were discussed. Further author derived VSS Inc-Cond based NN MPPT were developed on Matlab simulink. The output of FLC-Inc Cond as well NN based MPPT is great performance when compare to conventional system.
\end{abstract}

Keywords. Furry logic control, variable step incremental conductance, Neural Network, Photovoltaic, boost converter.

\section{Introduction}

Recent days the development of solar tracking system concentration on much because of greater awareness on people about current trend scare of air pollution, water pollution, dependent on fuel sources, etc[1]-[8]. The another side reduction of conventional sources such as coal, oil, gas it is making question on automobile as well power generating station[2]-[16]. So people are much concentrate to develop alternative energy sources through renewable energy source such as solar, wind, bio mass, bio gas, etc[3]-[6]. The renewable solar system available all days of throughout of year. It is available on every place, due to plenty of source one all fuel vehicle convert into electric vehicle[1]-[7]. Extraction of power not only depend on power

\footnotetext{
${ }^{1}$ Chandramouli A, Dept. of Electrical, Sathyabama Institute of Science Technology, Chennai,

Email: chandersrec@gmail.com.
} 
grid, with help of solar system cover $90 \%$ villages get electricity. Govt of India taking more initiative such as solar ambastor on October $2^{\text {nd }}$ to create awareness on how to install solar plant, as well how to trouble shoot the system, etc cover on the workshop. In this paper discuss how to extract maximum power from generating solar photovoltaic panel[11]-[18]. The extraction of maximum power from solar PV system is trend from past one degate. It start from conventional fractional open circuit voltage, short circuit current, perturb and observe, incremental conductance, artificial intelligence and optimization techniques. In this paper discussed two artificial intelligent MPPPT method to track the maximum power were proved.

\section{Methodology}

The suitable solution to track the maximum power point tracking is suggested by many methods. In this paper (K. Loukil et al, accepted October 2019 ) proposed FLC based MPPT tracking system. The proposed FLC system implement on FPGA controller. Further author tested on various climatic condition as well techniques to compare the proposed system. The controller consists of two inputs one is irradiation and temperature as input the output of the FLC MPPT controller produce the duty cycle as output, the produced duty cycle apply into Dc to Dc boost converter. FPGA is worked on hierarchical and methodological methods to satisfactory output. The authors said that the proposed system tracking speed, steady state, good response on rapid variation of solar insulation compare with conventional system. The proposed system not only good response as well reduce the execution time and faster upto 300 times compare with conventional processor. It produce more power at the output as well increase the channels.

In this paper author developed Incremental fuzzy logic system. Gnerally incremental conductance is simplicity of the algorithm but it contains few drawback. Such as low speed of convergence to touch the optimal position. And it will produce oscillation around the optimal condition as well momentary system move away from the maximum point or sudden variation of temperature and insulation. These drawback overcome by variable step size incremental came into the picture. In the variable step uses to divided into three category at starting large step, in middle average and last small and steady. In FLC there are two inputs at fuzzification place such as $\mathrm{I}(\mathrm{k})$ and $\mathrm{V}(\mathrm{k})$. the output of fuzzification is numeral value it send to decision as well rule base system. At final the variable step is generated from the FLC system. As usual $\mathrm{dP} / \mathrm{dV}$ determine the value of pulse width modulation of $\mathrm{DC}$ to $\mathrm{DC}$ converter. The incremental conductance algorithm is to determine the ratio of operating point to optimal point. Based on these concept developed the Error and Change of Error. (E1 and E2). this $\mathrm{dP} / \mathrm{dV}$ is negative it will be right of $\mathrm{MPP}, \mathrm{dP} / \mathrm{dV}$ is positive to left of MPP. Approximate zero at optimal center point. 


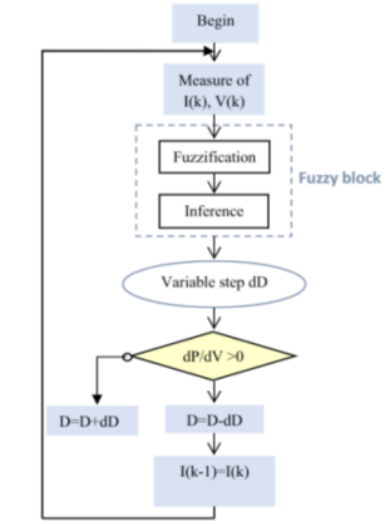

Figure 1. Inc-FLC Flowchart [1]

If (E1 is LG) and (E2 is LG), then (d is alpha)

(1)

Table 1. Inference Rule Table [1]

\begin{tabular}{llllll}
\hline & E2 & & & \\
\cline { 2 - 6 } E1 & LG & SN & Z & SP & LP \\
\hline LG & A & $2 \alpha / 3$ & $2 \alpha / 3$ & $2 \alpha / 3$ & $\alpha$ \\
SN & $2 \alpha / 3$ & $2 \alpha / 3$ & $2 \alpha / 3$ & $2 \alpha / 3$ & $\alpha$ \\
Z & A & $\alpha / 6$ & $2 \alpha / 3$ & $\alpha / 6$ & $\alpha / 6$ \\
SP & $2 \alpha / 3$ & $2 \alpha / 3$ & $2 \alpha / 3$ & $2 \alpha / 3$ & $2 \alpha / 3$ \\
LP & $\alpha / 6$ & $2 \alpha / 3$ & $2 \alpha / 3$ & $2 \alpha / 3$ & $\mathrm{~A}$ \\
\hline
\end{tabular}

In proposed Figure 1 shows after measurement of current and voltage of the PV panel connected to fuzzy block. The fuzzy block contains fuzzification and inference engine or rule system. The output of Fuzzy block connected to variable Incremental conductance system. In the FLC used five subset variables, zero, small, large positive as well negative. These fuzzy subsets are produce great flexiblity and higher sensitivity.

In the designed FLC system author assign the 3 steps (1) Small step is alpha/6, middle or average is 2. alpha/3, greater step is alpha. [alpha/6. 2.alpha/3, alpha]. The table has developed based on Incremental conductance concept. These table were implemented on if- than method. In the FLC Takagi-sugeno (T-S) method were considered to get accurate result.

\subsection{Methods to implement FLC in FPGA circuit}

Step 1: Develop algorithm on "Quartus tool environment using VHDL language": The developed FLC rules is encoded with help of VHDL language. It consists of seven prime control blocks as fig. 2 show in below. The seven blocks are inputs, fuzzification, acquistion, inference engine, determination of sign direction, PWM generator block as well duty ratio generator. The architecture of the sesigned commend processed by coding of each function system in VHDL integrated in the quartus environment. 


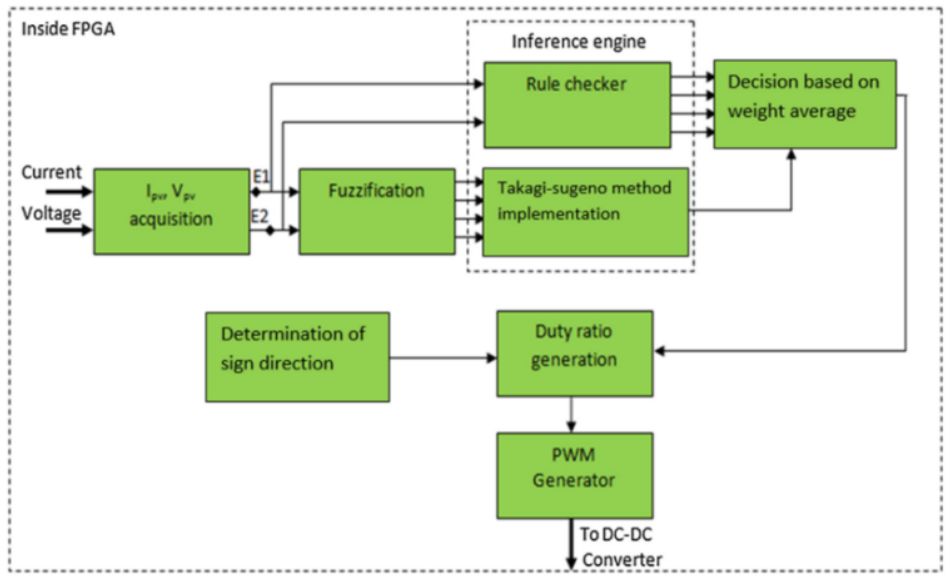

Figure 2. Model block diagram of FLC MPPT system[1]

Step 2: Simulate the circuit. The simulation step as shown in Fig.3 On Quartus tool. Do compilation and execution of designed algorithm show in Fig. 100Mhz stratix III FPGA board of altera running model were used.

Step 3: Prepare the experimental setup or structure. The authors were tested the proposed system on several panels uses to send variable V1, V2, V3.. and I1, I2, I3.. etc alternatively to calculate duty cycle. The interesting is author checked through various hardware controller such as Arduino Uno, Arduino Mega, Arduino Due, NIOS, FPGA. When we compare with arduino and GPGA has lowest time to execute the result. The summary of the proposed paper is FPGA controller suitable for largest number of PV channels.

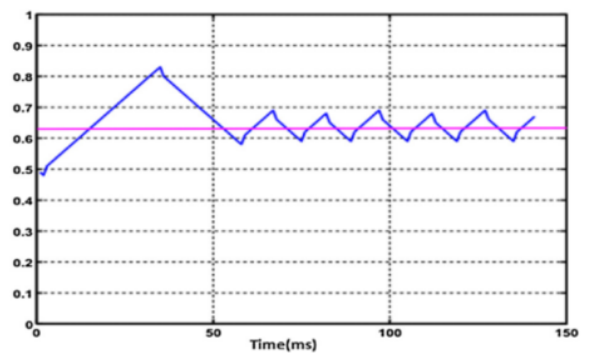

Figure 3. Developed PWM result of FPGA system[1]

Table 2. Fuzzy rule base [2]

\begin{tabular}{ccccccc}
\hline$E_{k}$ & $N L$ & $N S$ & $Z E$ & $P S$ & $P L$ \\
\hline$N E_{k}$ & & $Z E$ & $Z E$ & $P S$ & $N S$ & $N B$ \\
$N S$ & $Z E$ & $Z E$ & $Z E$ & $N S$ & $N B$ \\
$Z E$ & $P B$ & $P S$ & $Z E$ & $N S$ & $N B$ \\
$P S$ & $P B$ & $P S$ & $Z E$ & $Z E$ & $Z E$ \\
$P B$ & $P B$ & $P S$ & $N S$ & $Z E$ & $Z E$ \\
\hline
\end{tabular}


(Abdelghani Harrag and Sabir messalti, 2019) has developed Neuro-fuzzy incremental variable step size controller for PV system. Mode one is offline mode for testing different set of NN architecture and parameters to find the best. Model two optimal found NN controller is used to trace the optimal power of photovoltaic system through online. The input of NN is same as Inc-Cond inputs such as V, I. Here also the output of controller apply into boost converter. The results was proven the proposed VSS Inc Neuro fuzzy controller is better than classical Incremental conductance. The results were proven in terms of ripple, response time, oscillation accuracy, steady state, etc. The proposed system increases the output power and reduce the power losses.

\subsection{Variable step size fuzzy incremental system}

FLC speciality is operate on direct inputs instead of mathematical model. The FLC handling nonliterary without mathematics model. The output of fuzzy is PWM or duty cycle. In the proposed system developed 25 rules shown in Table. 2

$$
\begin{aligned}
& \mathrm{dp} / \mathrm{dv}=0 \\
& \mathrm{dP} / \mathrm{dv}=\mathrm{d}(\mathrm{I} . \mathrm{V}) / \mathrm{dv}=\mathrm{I}+\mathrm{V} . \mathrm{dI} / \mathrm{dV}=0 \\
& \mathrm{dI} / \mathrm{dV}>-\mathrm{I} / \text { Vat left of MPP }
\end{aligned}
$$

$\mathrm{dI} / \mathrm{dV}<-\mathrm{I} / \mathrm{V}$ at right of MPP

Mamdani inference system is used to create maximum-minimum creation strategy. Finally defuzzification block uses to convert numerial value into crisp output. In this paper centroid method of defuzzification. The output of the VS FLC Inc Cond MPPT as follows.

$$
\text { Dk=Dk-1 +FS* Del }
$$

where FS is scaling factor adjusted at the sampling period and DelD is fixed step size.

\section{Conclusion}

In this paper discussed two novel control system. Such as FLC- Inc-Cond based MPPT control system, and NN based MPPT control system. In the first half discussed development of fuzzy system with various controller such as FPGA, Arduino microcontroller. In the second half discussed about development of matlab simulink based NN MPPT control system. The output of NN control system is fast response compare to conventional fixed incremental conductance system. Scope of the paper. Instead of Variable step size Incremental conductance use conventional perturb and observe method. Second one the proposed FLC consists of 25 rules, these rules increases into 49 as well $3 \times 7$ HFNN frame to increase greater accuracy of the proposed system.

\section{References}

[1] K.Loukil et al .Design and implementation of reconfigurable MPPT fuzzy controller fro photovoltaic system .Ain shams Engineering jourrnal, accepted October 2019, P 1-10 .

[2] Abdelghani Harrag, and sabir Messalti .IC based Variable step size Neuro Fuzzy MPPT improving system performances .technologies and materials for Renewable Energy, Environment and Sustainability, TMREES18, Energy procedia 158,2019; p. 362-374.

[3] Gupta Abhishek kumar, et al .Review on widely used MPPT techniques for PV applications .International conference Innovation and challenges in cyber security, IEEE:2016 . 
[4] Osisioma Ezinwanne Fu Zhongwen Li Zhijun. Energy performance and cost comparison of MPPT techniques for Photovoltiac and other application. Energy Proc 2017, February, p. 297-303 .

[5] Wang P, Zhou Z, Cai M, Zhang J. An improved multistage variable step MPPT algorthm for photovoltaic system .International conference on computer science and electronics engineering ICCSEE, 2013.

[6] B.A. Kumar, M.S. Venkatesh and G.M. Muralikrishna, Optimization of Photovoltaic Power Using PID MPPT Controller Based on Incremental Conductance Algorithm, Power Electronics and Renewable Energy Systems, Lecture Notes in Electrical Engineering 326, DOI 10.1007/978-81-322-2119-7_78 p. 803-809,

[7] T. Radjai,et al .Experimental verification of P\&O MPPT algorithm with direct control based on Fuzzy logic cont rol using CUK converter.Int. Trans. Electr. Energ. Syst, 25(12),2015:3492-3508.

[8] G.N. Femia, G. Petrone, G. Spagnuolo, M. Vitelli .Optimization of perturb and observe maximum power point tracking method .IEEE Trans Power Electron20;2005;963-973.

[9] K. Ishaque, Z. Salam, G. Lauss . The performance of perturb and observe and incremental conductance maximum power point tracking method under dynamic weather conditions,Applied Energy $119 ; 2014$ ;228-236.

[10]K. S. Tey, S. Mekhilef, Modified incremental conductance MPPT algorithm to mitigate inaccurate responses under fast-changing solar irradiation level, Solar Energy $101 ; 2014 ; 333-342$.

[11]A.Chandramouli, V.Svachidambaranatham and R. Arulmurugan .Modelling and Design of Five Parameter Single Diode Photovoltaic Model with Artificial Intelligent MPPT Power System. International Journal of Recent Technology and Engineering IJRTE, Volume-8 Issue-2S8, August 2019 pp.1063-1068 DOI:10.35940/ijrte.B1014.0882S819

[12]Dr. R. Arulmurugan .Transformerless H-bridge inverter based PV system for harmonic current compensation . Journal of Electrical Engineering, Ver. 18.3.20, P.1-8, 2018, ISSN 1582-4594

[13] Swapna Sandaraju, Dr. R. Arulmurugan and a.v.v. Sudhakar .Grid-Connected Pv Wind Battery Based Framework With Multi Input Transformer Coupled Converter .International Journal of Advanced Science and Technology (IJAST)ISSN:2005-4238E-ISSN:2207-6360, Vol-127-June-2019,p- 285-291

[14]Dr. R. Arulmurugan .Analysis of Fuzzy-Logic MPPT Controller for Photovoltaic Application. Journal of Alternative and Renewable Energy Sources ; oct 2018 ,Volume 4 Issue 3, P. 1-15.

[15]Dr. R. Arulmurugan. Photovoltaic powered transformer less hybrid converter with active filter for harmonic and reactive power compensation. ECTI Transactions on Electrical Engineering, Electronics, and Communications, Vol.16, No.2, p.44-51, August 2018 ISSN: 1685-9545

[16] M Kavitha, V Sivachidambaranathan .Power factor correction in fuzzy based brushless DC motor fed by bridgeless buck boost converter .2017 International Conference on Computation of Power, Energy Information and Commuincation (ICCPEIC),2017, p 549-553.

[17] Dr. R. Arulmurugan, Dr. B. Rajender, B. Sathyavani, K. Balakrishna. An Overview of Converters and Inverters. International Journal of Engineering \& Technology-UAE, Vol. 7, issue.3.34,2018, p-992-994 ISSN:2227-524X.

[18] Arulmurugan R, Monika P. A simulation analysis of PV powered Inc-Cond MPPT based transformerless hybrid active filter for power quality improvement. IJRA, Vol. 6, No. 4, December 2017. Issn:2089-4856

[19] Kavitha.M and Sivachidambaranathan.V (2015) .Performance Analysis of Transformer-Less Two Phase Interleaved High Gain DC Converter using MPPT Algorithm .Indian Journal of science and Technology (ISSN 0974-6846) - Vol 8 (15), 61428, July 2015, p 1-8.

[20] Geetha.V and Sivachidambaranathan.V (2018).A single switch parallel Quasi resonant converter topology for induction heating application. International Journal of Power Electronics and Drive System (IJPEDS) (ISSN 2088-8694) - Vol. 9, No. 4, December 2018, pp. 1718 - 1724. 